\title{
Estudo de Caso: uma proposta para abordagem de funções da Química Orgânica no Ensino Médio
}

\author{
Juliana Alba \\ Tania Denise Miskinis Salgado \\ José Cláudio Del Pino
}

\begin{abstract}
Resumo
Este trabalho consiste na análise de uma experiência de aplicação do método de Estudo de Caso a uma turma de segundo ano do Ensino Médio de uma escola pública de Porto Alegre, como forma de abordagem das funções da química orgânica por meio do tema "Medicamentos". O objetivo desta proposta é desenvolver uma prática pedagógica que contribua para que o aluno tenha compreensão do conhecimento científico e perceba sua vinculação com a realidade que o cerca, facilitando dessa forma o aprendizado de conceitos químicos e favorecendo o fortalecimento de habilidades que possam instrumentálo para a tomada de decisão e o exercício da cidadania. Foram utilizados instrumentos de coleta de dados, antes e depois da realização das atividades, numa perspectiva metodológica de pesquisa qualitativa e quantitativa. Os resultados mostram que a estratégia didática de Estudo de Caso favoreceu aprendizagens conceituais, desenvolvimento de habilidades e motivou os estudantes a se envolveram nas atividades propostas nas aulas de química.
\end{abstract}

Palavras-chave: Estudo de Caso, ensino de funções orgânicas, desenvolvimento de habilidades.

\section{Abstract}

Case Study: a proposal to teach organic chemistry functions in high school

This work analyses the experience of applying the Case Study methodology in a second year class of a public high school in Porto Alegre for the study of organic functions by means of the theme "Medicaments". The proposal aims to develop a pedagogical practice, which allows the student to understand scientific knowledge and to perceive its relationship with the reality that surrounds him, supporting chemical concepts learning and the enhancement of abilities that can be useful for decision making and citizenship exercising. Instruments were used to collect data, before and after the realization of activities, in a quantitative and qualitative research perspective. The results show that the Case Study didactic approach favored conceptual learning, abilities enhancement, and motivated the students to involve in the activities proposed in chemistry classes.

Keywords: Case Study, organic functions teaching, abilities development. 


\section{Referencial Teórico}

As práticas pedagógicas nos diferentes contextos em que a escola está inserida devem ser pensadas e desenvolvidas com o propósito de promoverem o aprendizado, a compreensão e o interesse dos alunos pelos conteúdos. É comum, no entanto, ouvir professores relatarem a falta de motivação dos alunos em relação ao aprendizado e as dificuldades que os mesmos apresentam para entender os conceitos de química. Observa-se também, nas escolas, a indiferença na postura e fala de alguns educadores, que caracterizam o aluno como desinteressado, indisciplinado, irresponsável e veem o estudante como o principal gerador desse quadro que acaba por se configurar em, de um lado, professores frustrados e, de outro, alunos com baixo rendimento escolar.

O professor muitas vezes se acomoda diante de tais dificuldades. Mas os aspectos que tornam difícil a realização de um bom trabalho em sala de aula podem, muitas vezes, estar relacionados ao distanciamento entre o conhecimento científico que é apresentado pelo professor e as situações reais e concretas vivenciadas pelo aluno (DELIZOICOV; ANGOTTI, 1992).

Além disso, em relação a alguns obstáculos que interferem no sucesso da aprendizagem, estudos apontam que, mais do que as outras ciências, a Química tem uma linguagem caracterizada como "esotérica", decorrente da quantidade de nomes, símbolos e fórmulas que fazem parte dos conteúdos dessa disciplina (CHASSOT, 1995). Essas características, como se sabe, são importantes e necessárias, porém podem contribuir para tornar o ensino de química distante e pouco significativo para as situações reais vivenciadas pelo aluno e consequentemente podem fazer com que os estudantes percam o interesse pela disciplina.

Os estudantes podem ser motivados para a aprendizagem por meio de estratégias que vinculem o ensino de química com situações que fazem parte do seu dia-a-dia, propiciando uma interpretação e compreensão do mundo. Assim, os conteúdos de química podem ser mais interessantes e prazerosos, trazendo resultados desejados na aprendizagem, na medida em que o aluno encontrar, através do conhecimento químico, as respostas para as perguntas que fazem parte do seu mundo.

Dentro desse contexto, a escola e os professores devem estar cientes de seus papéis na formação dos educandos para além da sala de aula, fornecendo ferramentas para o desenvolvimento de habilidades que tornem o aluno um cidadão de ação social responsável, assim como é indicado nos Parâmetros Curriculares Nacionais para o Ensino Médio (BRASIL, 2002).

Para Delizoicov, Angotti e Pernambuco (2002), é importante que a sala de aula seja um espaço onde existam trocas reais entre alunos e professores, possibilitando um diálogo que permita o conhecimento sobre novas formas de compreender o mundo. O professor deve se focalizar em propostas de ensino que relacionem os conhecimentos científicos com a realidade do

R. B. E. C. T., vol 6, núm. 2, mai-ago.2013 ISSN - 1982-873X 
aluno e suas necessidades, possibilitando que os estudantes desenvolvam condições de agir como cidadãos, interferindo no mundo com ações e decisões responsáveis.

Considerando ser um dos compromissos da educação dar condições para o exercício da cidadania, Delizoicov e Angotti (1992) apontam que o ensino deve se nortear pela capacidade de instrumentar o aluno como um futuro cidadão para melhor compreender a realidade onde se insere, possibilitando-Ihe uma atuação consciente sobre ela. Para tanto, os autores descrevem uma série de habilidades que, segundo eles, precisam ter a oportunidade de ser desenvolvidas durante as aulas, pois são, entre outras, as responsáveis por instrumentar o aluno como futuro cidadão: observação, classificação, registro e tomada de dados, construção de tabelas, análise de informações, síntese, aplicação. Cabe salientar que não são essas as únicas habilidades responsáveis por enriquecer a formação do aluno como cidadão, mas segundo os autores, são elas que têm mais relação com as disciplinas de ciências e, portanto, precisam ser desenvolvidas com mais atenção nessas aulas.

Do mesmo modo, em outros estudos sobre o comprometimento que deve ter a educação escolar com a formação dos estudantes, Lipman (1995) enfatiza a impossibilidade de se acreditar que os alunos poderão aprender a pensar melhor por meio de um processo educacional que pouco os estimula a pensar, ressaltando, ainda, que muitos professores se negam a reformular seus planos de aula, pois segundo tais educadores seria esse um esforço em vão quando se visa aprimorar as habilidades que os alunos já deveriam ter trazido para a sala de aula. Nesse contexto, Lipman (1995) também reconhece quatro grupos de habilidades que se tornam relevantes para os objetivos educacionais, sugerindo que os alunos podem fortalecê-las e aperfeiçoá-las através de atividades propostas pelos professores em sala de aula: habilidade de investigação, habilidade de raciocínio, habilidade de organização de informações, habilidade de tradução.

Convém destacar, ainda, que muitas das habilidades descritas são identificadas nas matrizes de referência do ENEM (BRASIL, 2009). Assim, diante das exigências desse mecanismo de avaliação, que é um dos objetivos de muitos estudantes do Ensino Médio regular, é necessário que tais habilidades sejam trabalhadas e desenvolvidas visando, além da formação do aluno como cidadão, também o bom desempenho dos estudantes que pretendem realizar essa prova, a qual vem sendo adotada como critério de seleção por muitas Instituições de Ensino Superior, em substituição ao vestibular.

Se parece difícil para o profissional da educação se comprometer com a utilização de métodos pedagógicos que fortaleçam essas habilidades, a educação envolve também outras responsabilidades, pois ao adquirir uma habilidade o aluno ainda corre o risco de decidir utilizá-la mal (LIPMAN, 1995). Na vida real, constantemente ocorrem situações nas quais é preciso tomar decisões que requerem reflexão e análise a fim de que se possa encontrar uma boa solução. 0 contexto escolar do Ensino Médio é constituído por jovens que estão em fase de amadurecimento 
e nem sempre estão preparados para tomar decisões conscientes sobre as situações enfrentadas no seu dia-a-dia. Nesse aspecto, segundo Freire (1996), o professor pode intervir com uma pedagogia centrada em experiências estimuladoras de decisão, contribuindo para a formação do aluno como cidadão. Assim, considerando que as decisões tomadas pelas pessoas na vida real podem influenciar a construção de um mundo melhor, é desejável que as atividades elaboradas pelos educadores se aproximem das situações reais, possibilitando que os alunos desenvolvam sua capacidade de tomada de decisão.

Santos e Mortimer (2001) propõem um ensino de ciências que possa contribuir para a tomada de decisão com vistas a uma ação social responsável e apresentam alguns modelos normativos para o processo de tomada de decisão. Dentre os modelos descritos, encontra-se o proposto por Kortland (1996 apud SANTOS; MORTIMER, 2001), segundo o qual as atividades de ensino que visam desenvolver a capacidade de tomada de decisão deveriam seguir todas as etapas apresentadas na Figura 1.

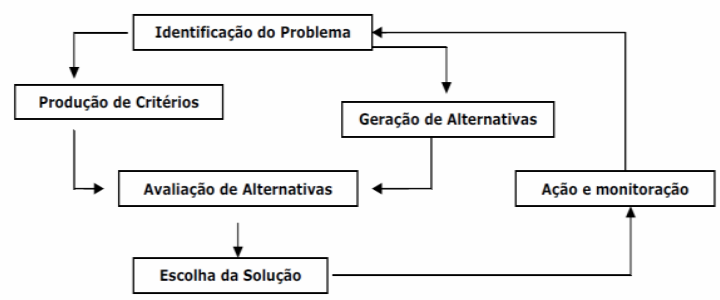

Figura 1: Modelo normativo do processo de tomada de decisão de Kortland (1996 apud SANTOS; MORTIMER, 2001).

De acordo com Kortland (1996 apud SANTOS; MORTIMER, 2001, p. 4): "Tomada de decisão pode ser compreendida como a maneira racional de escolha entre meios alternativos de ação (relativas a questões sociais ou públicas), os quais requerem um julgamento em termos de seus valores." A observação do modelo apresentado na Figura 1 sugere que a tomada de decisão seja feita de modo que o aluno possa avaliar fatores positivos e negativos das alternativas para a solução do problema, permitindo que ele seja capaz de sustentar seus argumentos de maneira reflexiva.

Com a finalidade de possibilitar o desenvolvimento de algumas das habilidades, como as relatadas em trabalhos como os de Lipman (1995) e Delizoicov e Angotti (1992), contribuir para a capacidade de tomada de decisão e para o entendimento dos conceitos de química, uma das proposições metodológicas de natureza pedagógica encontradas na literatura é o Estudo de Caso, descrito por Sá e Queiroz (2009), pois oferece a oportunidade de os alunos entrarem em contato com situações e problemas reais, possibilitando o desenvolvimento do pensamento crítico e de habilidades, além de facilitar a aprendizagem dos conceitos da área em questão. 0 método de Estudo de Caso utiliza narrativas (os casos) que descrevem situações vivenciadas por seus 
personagens, os quais precisam tomar decisões importantes em relação a um determinado assunto (SÁ; QUEIROZ, 2009).

Segundo essas autoras, para que esta atividade traga os resultados esperados para o processo de aprendizagem, é importante que o caso seja elaborado de maneira que o aluno se identifique com o contexto e com os personagens da narrativa. Essa aproximação do contexto do caso com a realidade do aluno pode incentivar e estimular os alunos na busca de alternativas e consequentemente na tomada de decisão, que os levarão à solução do caso. Para tanto, na elaboração de um "bom caso", segundo Herreid (1998a apud SÁ; QUEIROZ, 2009, p. 19) é necessário que sejam considerados os seguintes aspectos:

"deve ter utilidade pedagógica - deve ser útil para o curso e para os estudantes; é relevante ao leitor - os casos escolhidos devem envolver situações que possivelmente os estudantes saibam enfrentar. Isso melhora o fator empatia e faz do caso algo que vale a pena estudar; desperta o interesse pela questão: para que um caso pareça real, deve descrever um drama, um suspense. $O$ caso deve ter uma questão a ser resolvida; deve ser atual - deve tratar de questões atuais, que levem o estudante a perceber que o problema é importante; é curto - os casos devem ser suficientemente longos para introduzir um fato, mas não tão longos que possam provocar uma análise tediosa; provoca um conflito - a maioria dos casos é fundamentada sobre algo controverso; cria empatia com os personagens centrais - as características escolhidas para os personagens devem influenciar na tomada de decisões; força uma decisão - deve haver urgência e seriedade envolvida na solução dos casos; tem generalizações - deve ter aplicabilidade geral e não ser específico para uma curiosidade apenas; narra uma história - com desfecho no seu final; inclui citações - é a melhor maneira de compreender uma situação e ganhar empatia para com todos os personagens. Deve-se adicionar vida e drama a todas as citações."

Tais aspectos auxiliam o professor na elaboração de um caso e a literatura recomenda que eles sejam explorados para que os objetivos da aplicação deste método sejam alcançados.

Por meio de uma análise da utilização de Estudo de Caso no ensino de ciências, Herreid (1998a apud SÁ; QUEIROZ, 2009) elaborou uma classificação para as estratégias que comumente são utilizadas na aplicação desse método, entre as quais as autoras destacam: formato de aula expositiva - na qual o caso é apresentado pelo professor; formato de discussão - o caso é exposto pelo professor e os alunos são interrogados a fim de que tragam ideias que contribuam para a solução do caso; formato de atividades em pequenos grupos - os casos são investigados e analisados por grupos de alunos que precisam trabalhar juntos para chegar a uma solução. Por meio de pesquisas individuais e coletivas, os grupos analisam informações até chegar à solução do caso, sendo que o professor age como orientador durante as discussões. 
De acordo com Sá e Queiroz (2009, p. 19), durante a aplicação do método em questão, os estudantes têm a oportunidade de realizar as seguintes etapas: "identificar e definir o problema; acessar, avaliar e usar informações necessárias à solução do problema; apresentar a solução do problema."

A utilização do método de Estudo de Caso sugere que a prática do educador deve ser um instrumento de construção do conhecimento, na medida em que o educador se preocupa em pesquisar quais são os interesses do aluno, além de enquadrar esses interesses aos conteúdos que organizam a disciplina em questão, possibilitando que a participação e o envolvimento dos alunos sejam elementos indispensáveis à sua aprendizagem. Dessa forma, abrem-se caminhos para formação de um ambiente onde existam trocas reais entre professores e alunos.

Silva, Oliveira e Queiróz (2011) aplicaram o método de Estudo de Caso para trabalhar, com alunos de Ensino Médio, a questão da conscientização ambiental relacionada à poluição de ambientes aquáticos, refletindo sobre as prováveis causas de problemas reais e envolvendo a tomada de decisão e a sugestão de possíveis soluções para o caso por parte dos alunos, desenvolvendo habilidades de investigar, de solucionar problemas, de realizar trabalhos em grupo e de comunicação oral.

No presente trabalho, o método foi empregado para trabalhar especificamente um conteúdo químico tradicionalmente abordado nas salas de aula do ensino médio, que são as funções da Química Orgânica. Ao mesmo tempo, como era necessário escolher um tema que contextualizasse os casos a serem elaborados, trabalhou-se com o tema medicamentos. Esse tema se mostra interessante para a abordagem do conteúdo de funções orgânicas por permitir a contextualização de um assunto que é comumente abordado, em sala de aula, de forma centrada na memorização. Com este propósito, o tema medicamentos já foi sugerido por outros autores para o trabalho, tanto teórico quanto experimental, de funções orgânicas (PAZINATO et al., 2012). Livros didáticos também utilizam fórmulas de princípios ativos de medicamentos na exemplificação de aplicações das funções orgânicas (PERUZZO; CANTO, 1998, SANTOS; MÓL, 2005, USBERCO; SALVADOR, 2009). Entretanto, a abordagem por meio do Estudo de Caso, aqui apresentada, diferencia-se das demais por trabalhar o assunto de forma a não apenas contextualizar, mas principalmente tornar esse conteúdo químico relevante para os estudantes do ensino médio de uma escola pública da periferia de uma grande capital do sul do País.

Considerando o compromisso que têm a escola e o professor com a formação do cidadão, neste trabalho a proposta de Estudo de Caso foi adaptada a fim de contribuir para o desenvolvimento de habilidades de análise, de investigação, de tomada de decisão, entre outras destacadas em trabalhos como os de Lipman (1995) e de Delizoicov e Angotti (1992) como necessárias para a formação do cidadão. Ao mesmo tempo, a estratégia didática utilizada para abordar o conteúdo de funções da Química Orgânica busca superar modelos puramente 
descritivos e centrados em memorização, normalmente adotados no ensino baseado em aulas tradicionais.

Nesta perspectiva, o objetivo desta proposta é desenvolver uma prática pedagógica que contribua para que o aluno perceba a vinculação do conhecimento científico com a realidade que o cerca, facilitando dessa forma o aprendizado de conceitos químicos e favorecendo o fortalecimento de habilidades que possam instrumentá-lo para o exercício da cidadania. Pretende-se que o aluno perceba e compreenda a ampla relação do estudo da química com fatores sociais, tecnológicos e éticos que fazem parte da sua realidade. É esperado que essa aproximação promova no aluno o desenvolvimento de habilidades, de sua capacidade de tomada de decisão responsável, contribuindo para sua formação como cidadão, produzindo resultados significativos para a aprendizagem e podendo fazer com que o conteúdo se torne de mais fácil compreensão.

\section{Proposta Metodológica de Pesquisa}

Esta pesquisa se constitui também, metodologicamente, como um estudo de caso, que se caracteriza por um estudo em situação bem delimitada, devendo ter seus contornos claramente definidos. Em um caso se tem interesse próprio, singular. Ele se constitui numa unidade dentro de um sistema mais amplo (LÜDKE; ANDRÉ, 1986). Para se obter os dados empíricos desta pesquisa se utilizaram instrumentos de coleta de informações que foram analisadas, apropriando-se dos referenciais teóricos da pesquisa qualitativa (LÜDKE; ANDRÉ, 1986; BOGDAN; BIKLEN, 1994) e da pesquisa quantitativa (GATTI, 2004). Os critérios de análise foram definidos em função do conteúdo das respostas dos alunos e dos objetivos da pesquisa.

Em relação à metodologia quantitativa, entende-se que ela envolve considerar, como ponto de partida, dois aspectos: "primeiro, que os números, frequências, medidas, têm algumas propriedades que delimitam as operações que se pode fazer com eles, e que deixam claro seu alcance; segundo, que as boas análises dependem de boas perguntas que o pesquisador venha a fazer, ou seja, da qualidade teórica e da perspectiva epistêmica na abordagem do problema, as quais guiam as análises e as interpretações" (GATTI, 2004).

Foram usadas como referência para a análise textual discursiva as proposições de Moraes e Galiazzi (2011), Lüdke e André (1986) e Bogdan e Biklen (1994). Na fase inicial de análise buscouse construir um conjunto de categorias que a leitura das informações obtidas pela utilização de instrumentos de coleta de dados mostrou ser coerente e representativo das unidades de significado extraídas das informações expressas pelos participantes da pesquisa. A partir desta categorização, em relação à aplicação dos demais instrumentos, os resultados foram transcritos, 
lidos e deles retiradas as falas significativas para ampliar uma ou outra categoria de análise. A partir desta análise procurou-se produzir novas compreensões sobre os fenômenos e discursos observados e identificaram-se com maior clareza os sentidos produzidos pelas manifestações dos sujeitos da pesquisa (MORAES; GALIAZZI, 2011).

\section{Proposta Pedagógica}

Esta atividade foi realizada junto a uma turma de segundo ano do ensino médio de uma escola pública estadual de Porto Alegre, durante dois meses, englobando nove horas-aula. Antes da aplicação desta proposta, a turma havia apenas iniciado o estudo de química orgânica. As funções orgânicas, que não haviam sido abordadas até aquele momento, foram trabalhadas exclusivamente por meio do método de Estudo de Caso.

O tema selecionado para construção do caso foi "medicamentos", com enfoque na automedicação, por se relacionar a problemas reais dos cidadãos, possibilitando a problematização e contextualização de aspectos científicos, tecnológicos e sociais, bem como o entendimento de conceitos básicos da química orgânica e a abordagem e reconhecimento das funções orgânicas.

Como fontes de inspiração para produção do caso foram utilizados: uma reportagem divulgada na seção Saúde e Bem Estar do sítio da revista Época em 21/09/2009 (LOPES, 2009) e um artigo encontrado no site de buscas acadêmicas SCIELO (PEREIRA et al., 2007).

Para elaboração do caso, foram considerados alguns dos aspectos descritos por Herreid (1998a apud SÁ; QUEIROZ, 2009, p. 19), como importantes para um "bom caso". Esses aspectos estão destacados no Apêndice 1 para o caso que foi elaborado para essa atividade.

Considerando as etapas que o referencial teórico sugere para a aplicação do método de Estudo de Caso, os alunos tiveram a oportunidade de participar dos três momentos: identificar e definir o problema; acessar, avaliar e usar informações necessárias à solução do problema; apresentar a solução do problema. Inicialmente, foi explicado aos estudantes como seria realizada a atividade. Logo após, foi aplicado um questionário (Apêndice 2), para que os alunos respondessem individualmente, e que tinha por objetivo avaliar as informações e conceitos prévios que os alunos possuíam acerca do tema.

Em seguida, foi solicitado que os alunos se organizassem em quatro grupos, de acordo com suas próprias afinidades, e foi distribuída uma cópia para cada aluno do Estudo de Caso intitulado "Automedicação: uma opção perigosa!" (Apêndice 1). Os alunos acompanharam a leitura do caso, feita pela professora e acompanhada de esclarecimento de algumas dúvidas. Foi proposta uma discussão entre os integrantes de cada grupo para que os mesmos identificassem e definissem o problema que estava sendo abordado no caso e qual seria o papel de cada grupo na busca da sua 
solução. Foi informado que ao final de toda a atividade cada grupo deveria fazer uma apresentação dos resultados e entregar por escrito os dados e argumentos que os levaram à solução do caso. Ficou a critério de cada grupo definir a forma como o trabalho seria apresentado.

Na segunda etapa, cada grupo ficou responsável por pesquisar um dos medicamentos relatados no caso e foi distribuída para cada grupo uma embalagem do respectivo medicamento com sua bula. Em seguida, foram apresentados dois vídeos que correspondiam a duas reportagens: uma exibida pelo Jornal Hoje, em 07/07/2010 (Uso contínuo de analgésicos pode agravar doenças e causar problemas renais, disponível no seguinte endereço eletrônico: http://video.globo.com/Videos/Player/Noticias/0,Gim1307925-7823-uso+continuo+de+analgesicos+ pode+agravar+doencas+e+causar+problemas+renais,00.html) e outra exibida no Bom Dia Brasil em 07/09/2010 (Automedicação pode ser hábito perigoso, disponível no seguinte endereço eletrônico: http://video.globo.com/Videos/Player/Noticias/0,,GIM1332637-7823-automedicacao+ pode+ser+habito+perigoso,00.html). As duas reportagens traziam uma discussão e alertavam sobre a automedicação, por meio de entrevistas e relatos de pessoas que se automedicam.

Após a exibição dos vídeos houve uma apresentação em slides, preparada pela professora, com o objetivo de estimular a reflexão dos alunos sobre a automedicação. A seguir, foram identificados os princípios ativos e as respectivas fórmulas estruturais de alguns medicamentos que não pertenciam ao Estudo de Caso. No final da apresentação foi distribuído um questionário (Apêndice 3) que foi elaborado de acordo com o modelo proposto por Kortland (1996 apud SANTOS; MORTIMER, 2001), que visa orientar a tomada de decisão dos alunos. Em seguida, foi entregue para cada grupo uma lista de livros (disponibilizados no local onde a atividade estava acontecendo) e sítios da internet, nos quais os alunos poderiam pesquisar os dados que os levariam à solução do caso. Dispondo de todo esse material, os alunos começaram a busca das informações que julgavam importantes para a solução do caso.

No encontro seguinte, os grupos trouxeram informações que pesquisaram em casa, mas existiam muitas dúvidas, visto que tanto o questionário como o próprio Caso tratavam, entre outros assuntos, de funções orgânicas, as quais ainda não tinham sido estudadas por eles, mas eles perceberam que seria importante terem esse conhecimento. Assim, a partir das informações obtidas pelos alunos sobre a fórmula estrutural do respectivo princípio ativo do medicamento, começou-se a abordagem do conteúdo de funções orgânicas. Para isso, cada grupo recebeu a fórmula estrutural do princípio ativo do medicamento que estavam pesquisando, desenhada em tamanho grande em uma cartolina, de forma que facilitasse a visualização de todos os detalhes da estrutura da molécula.

Iniciou-se a seguir a apresentação de slides intitulada "Química nos medicamentos: Funções Orgânicas". Cada função orgânica foi apresentada tendo como base a fórmula estrutural do princípio ativo de um medicamento que não estava relacionado com o caso e que foi escolhido 
com base na primeira questão do questionário inicial. O conteúdo dos slides foi entregue na forma impressa, para que os alunos tivessem o registro dos conceitos que foram trabalhados.

No encontro seguinte os alunos foram levados até a sala de informática para que pesquisassem as informações que ainda faltavam para chegar à solução do caso. Nesse mesmo encontro, os grupos começaram a se organizar para a apresentação que teria início na próxima aula. A forma de apresentação da solução do caso, terceira etapa, ficou a critério de cada grupo, sendo auxiliados pela professora quando necessário. Após as apresentações foi aplicado um novo questionário (Apêndice 4) com o objetivo de avaliar os resultados do trabalho.

\section{Resultados e Discussão}

Dos trinta e cinco alunos matriculados na turma, apenas dezessete frequentavam regularmente as aulas, mas o questionário inicial foi respondido pelos treze alunos que se encontravam em sala de aula no dia em que teve início a atividade.

$\mathrm{Na}$ pergunta 1, que buscava verificar quais eram os medicamentos mais comuns encontrados nas casas dos alunos, eles poderiam assinalar mais de uma opção e as respostas, de acordo com a Figura 1, permitiram observar que os medicamentos que seriam abordados no Estudo de Caso eram de conhecimento e uso dos alunos.

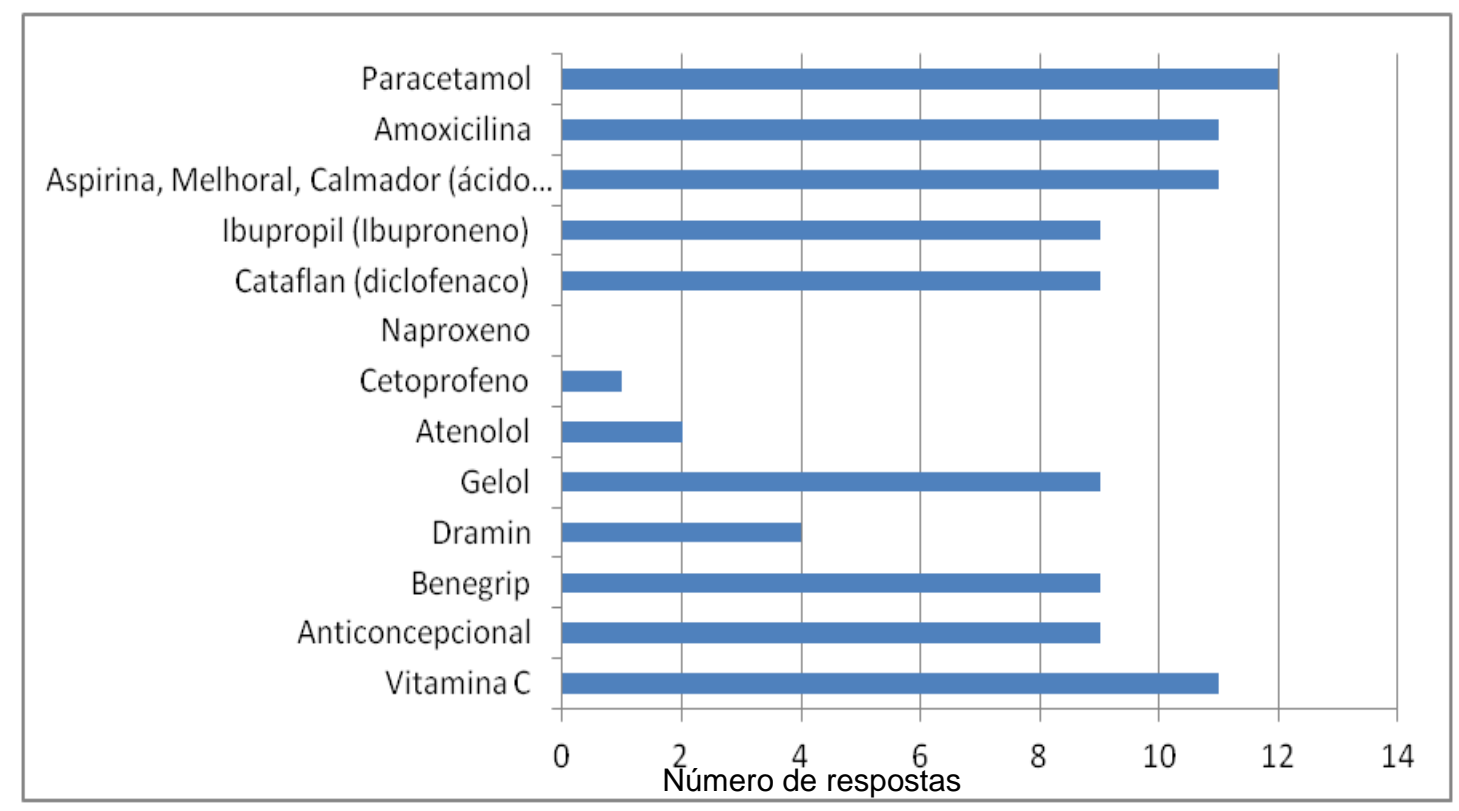

Figura 1 - Medicamentos mais utilizados e conhecidos pelos alunos.

Quando questionados sobre quem receitava os medicamentos que eles costumavam utilizar, os alunos também poderiam escolher mais de uma alternativa. A Figura 2 informa que o médico é geralmente quem receita os medicamentos, porém todas as outras alternativas também foram bastante assinaladas: mãe/pai e o farmacêutico. 


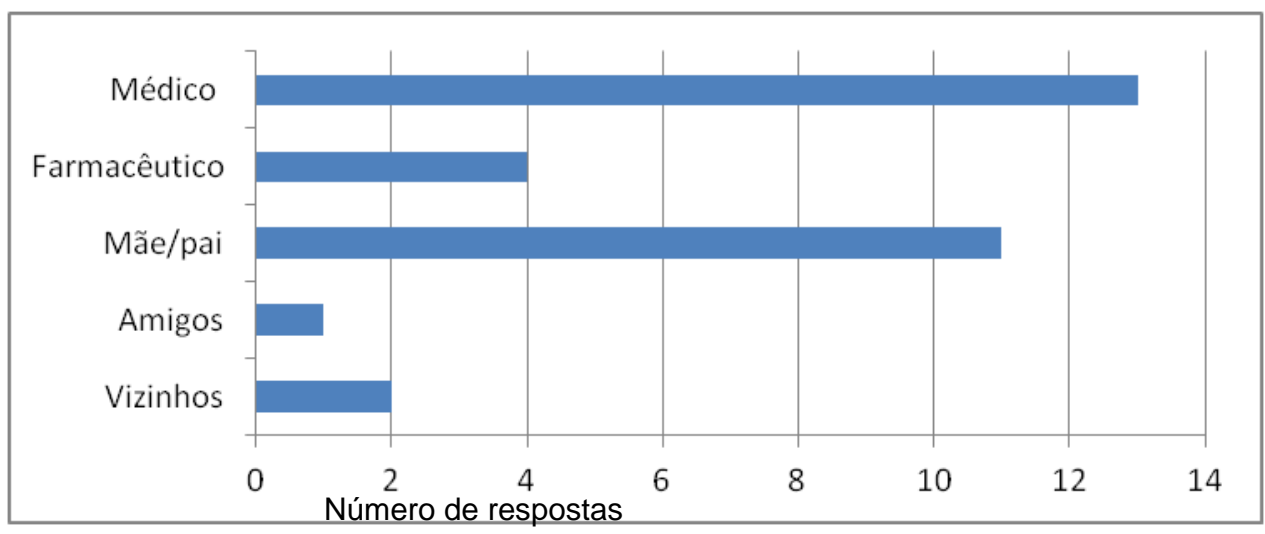

Figura 2 - Respostas dos alunos: quem receita os medicamentos que eles utilizam.

Em relação à pergunta seguinte do mesmo questionário, a maioria dos alunos concorda com o fato de que existe relação entre inovações tecnológicas no campo dos medicamentos com a química. Entre as justificativas apresentadas pelos alunos para essa relação, pode-se citar: "Todos os medicamentos têm química, são feitos por químicos", "os medicamentos são compostos químicos misturados", "a química ajuda a criar medicamentos, gerando lucro para as farmácias", ou ainda, "os medicamentos devem ser usados, testados e comparados pra que sejam usados com tranquilidade pelo consumidor".

Verifica-se nas respostas dos alunos que os mesmos têm muitos medicamentos em suas casas, citando entre outros, analgésicos e anti-inflamatórios; que não têm o hábito de ler a bula do medicamento; que são majoritariamente indicados por outras pessoas (58\%) que não o médico, caracterizando uma situação de automedicação. Este momento se constitui estratégico para motivar os estudantes a participar ativamente da proposta de organização do trabalho, segundo Delizoicov e Angoti (1992), aproximando professores e alunos para uma releitura do cotidiano destes à luz do conhecimento científico.

A apresentação das reportagens e dos slides, que ocorreram logo após a exposição do caso, de acordo com as observações da professora/pesquisadora, foram motivadoras, pois os alunos relataram fatos familiares envolvendo a automedicação e durante as apresentações, inclusive, percebia-se uma agitação entre os grupos, que tentavam encontrar o nome do princípio ativo do medicamento que fazia parte do estudo de caso na bula que havia sido entregue para cada grupo.

Por ser um problema que envolvia muitos conceitos e como estavam à disposição dos alunos diferentes fontes de pesquisa, observou-se que o questionário de orientação para a tomada de decisão (Apêndice 3 ) foi importante para a realização da atividade, pois todos os grupos se basearam nas questões propostas para chegar à solução, evidenciando que os alunos 
provavelmente teriam dificuldade para pesquisar e organizar informações se não tivessem recebido tais orientações.

Foi possível observar que, enquanto a apresentação da professora ocorria, os alunos tentavam, com grande entusiasmo, identificar os grupos funcionais presentes nas moléculas que correspondiam ao princípio ativo dos medicamentos que estavam pesquisando, bem como qual ou quais eram as funções orgânicas correspondentes. No final dessa abordagem, foi solicitado aos alunos que pesquisassem, na bibliografia disponibilizada, outras substâncias, além dos medicamentos, que apresentavam o grupo funcional e a correspondente função orgânica que eles tinham identificado nos respectivos medicamentos. Essa tarefa foi importante, pois por ser um conceito novo, os alunos poderiam pensar que as funções orgânicas eram características apenas dos medicamentos. Eles trouxeram exemplos de substâncias como por exemplo, proteínas, cravo da índia, vinagre, desinfetantes, álcool, substâncias que dão aroma às frutas, cosméticos, entre outras, fazendo com que aprimorassem seus conceitos, relacionando as funções orgânicas com substâncias e materiais que utilizavam cotidianamente. À medida que os estudantes se envolvem na busca de informações sobre o conhecimento químico acerca de funções da química orgânica e relacionam com substancias que utilizam no seu dia-a-dia, minimizam o hermetismo conceitual da química (Chassot, 1995).

Todos os quatro grupos apresentaram a solução do caso, conforme será relatado a seguir, tendo cada grupo adotado uma estratégia de apresentação diferente.

O grupo que ficou responsável pelo ácido acetilsalicílico fez uma apresentação de slides rica em detalhes, pois os alunos compararam as informações presentes no Estudo de Caso com as informações encontradas referentes ao medicamento que pesquisaram.

O grupo que ficou responsável pelo paracetamol, além de uma apresentação de slides, na qual expuseram as informações que os levaram à solução do caso, apresentou um vídeo reproduzindo a narrativa do Caso, no qual os personagens eram os próprios alunos e a mãe de uma das alunas atuou no papel da mãe de Diego. Nesse vídeo, abordaram a tomada de consciência da mãe de Diego quanto à automedicação e algumas informações que os levaram a crer que o paracetamol não era o medicamento responsável pelos sintomas da paciente.

O grupo responsável pelo anticoncepcional Ciclo 21 (etinilestradiol) concluiu que esse era, possivelmente, o medicamento responsável pelos sintomas apresentados pela mãe de Diego, conforme já era previsto pela professora que elaborou o Estudo de Caso. Esse grupo fez uma apresentação utilizando cartazes, que continham as principais informações que os levaram à solução do caso.

Os alunos do quarto grupo, responsável pelo medicamento Cataflan (Diclofenaco), utilizaram a lousa para desenhar a fórmula estrutural do princípio ativo do medicamento, apontando as informações que os levaram à solução do caso.

R. B. E. C. T., vol 6, núm. 2, mai-ago.2013 ISSN - 1982-873X 
Todos os grupos conseguiram decidir corretamente se o medicamento que estavam pesquisando era ou não o responsável pelos sintomas da mãe de Diego. As apresentações incluíram os conceitos envolvendo funções orgânicas, as informações sobre o medicamento e a avaliação dessas informações pelos alunos. O vídeo preparado por um dos grupos foi muito elogiado pelos colegas. Ainda, de acordo com os relatos dos alunos, eles não haviam tido a oportunidade, naquele ano, de prepararem apresentações utilizando recursos como um software para elaborar uma apresentação de slides, o que também contribuiu para aumentar a motivação dos estudantes em relação à apresentação dos trabalhos.

Após o término das apresentações, para o fechamento das atividades, foi aplicado um questionário (Apêndice 4), com o objetivo de avaliar a contribuição do método de Estudo de Caso no entendimento e compreensão dos conteúdos pelos alunos, bem como no desenvolvimento de habilidades de análise, de raciocínio, de organizar informações, de classificação, de investigação, de tomada de decisão, como foi apontado no referencial teórico. Dos dezessete alunos que frequentavam as aulas regularmente, quatorze estavam presentes no fechamento da atividade e responderam ao questionário.

A primeira pergunta foi elaborada para verificar se o método de Estudo de Caso contribuiu para a assimilação das características das funções orgânicas e dos seus correspondentes grupos funcionais. Dos quatorze alunos que responderam o questionário, dez apresentaram corretamente o nome das funções orgânicas que citaram e os grupos funcionais correspondentes. Um dos alunos desenhou corretamente alguns grupos funcionais, mas não soube relacioná-los com os nomes das funções orgânicas correspondentes e outros três alunos apresentaram incorretamente apenas uma das funções orgânicas que citaram: a função fenol, representando incorretamente o anel benzênico. Os resultados corroboram que este método de ensino é facilitador da aprendizagem de conceitos nas áreas de conhecimento em que se aplica esta proposta didática, conforme descrito por Sá e Queiroz (2009).

A segunda pergunta questionava os alunos sobre as atitudes que eles tomariam antes de utilizar um medicamento. Pela análise das respostas, observou-se que todos os alunos parecem estar conscientes dos perigos que pode sofrer uma pessoa que se automedica. Em todas as respostas encontrou-se em comum a orientação de que é necessário consultar o médico antes de se medicar e sugeriram a ida aos postos de saúde como uma alternativa para as pessoas que não têm condições de consultar o médico, assim como a leitura da bula do medicamento antes de ingeri-lo. Esta mudança é positivamente significativa quando comparada com as respostas dos alunos ao questionário inicial. Santos e Mortimer (2001) enfatizam que propostas desta natureza, como as vivenciadas no contexto desta investigação, podem contribuir para a tomada de decisão com vistas a uma ação social responsável.

As avaliações dos estudantes a respeito da proposta que foi apresentada foram colhidas através das perguntas três e quatro. Na questão três, foram apresentadas aos alunos algumas 
afirmativas que dizem respeito a habilidades, conceitos e capacidades que se pretendia aprimorar com o método de Estudo de Caso. Na Figura 3, mostra-se o grau de concordância dos alunos com as afirmações apresentadas.

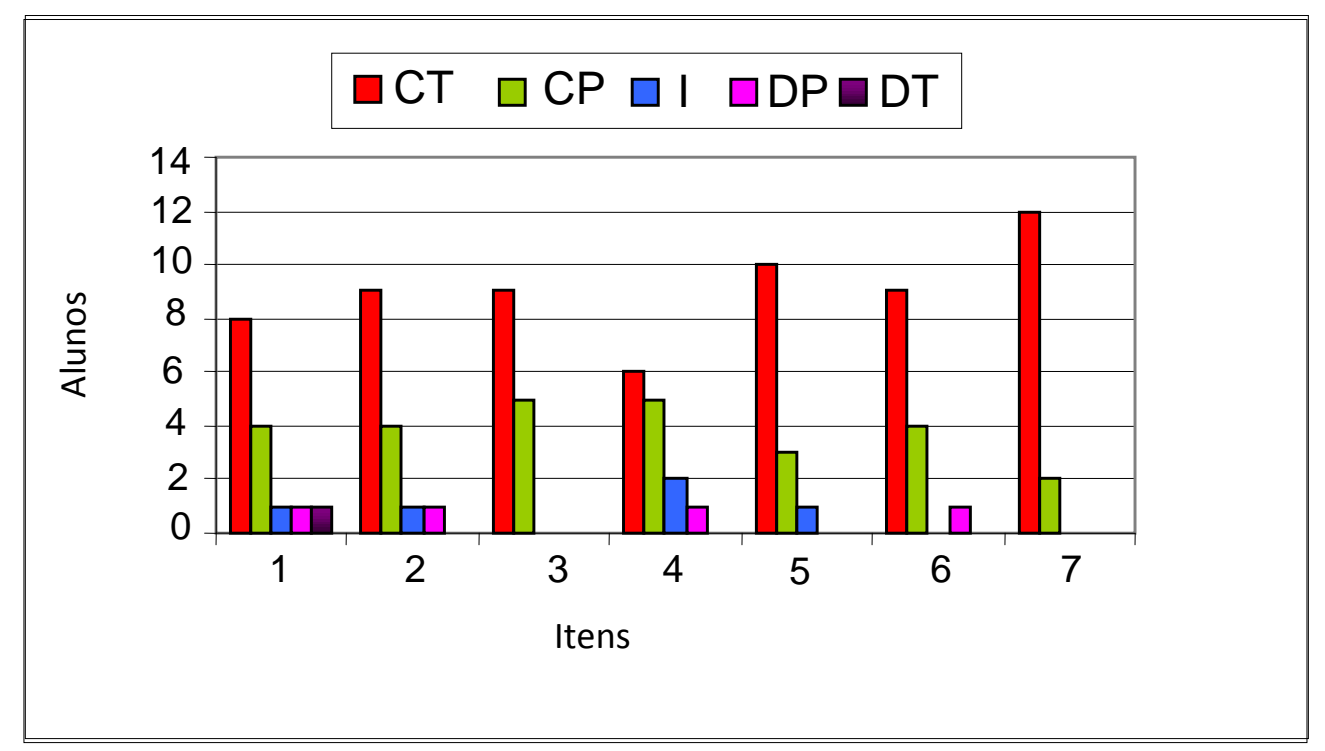

Figura 3 - Grau de concordância dos alunos em relação às afirmações apresentadas nos itens que vão de 1 a 7 (vide Apêndice 4), sobre o método de Estudo de Caso (CT=Concordo Totalmente; $C P=$ Concordo Parcialmente; $I=I$ Indeciso; $D P=$ Discordo Parcialmente; $D T=$ Discordo Totalmente).

A análise da Figura 3 permite afirmar que nos itens 1, 2, 3, 4 e 5, que diziam respeito ao desenvolvimento das habilidades de investigação, organização de informações, raciocínio, análise e classificação, respectivamente, a maioria dos alunos registrou respostas favoráveis à contribuição do método de Estudo de Caso para o seu aprimoramento. Tais habilidades são consideradas por Lipman (1995) relevantes para se alcançar objetivos educacionais, como a educação científica para o exercício da cidadania. Apesar de alguns itens apresentarem algumas respostas desfavoráveis à contribuição do método, o resultado geral aponta para a efetividade da proposta de ensino no desenvolvimento das referidas habilidades, na opinião dos alunos. No item 6, apenas um aluno discordou da contribuição do método para o desenvolvimento da capacidade de solucionar problemas e tomar decisões diante de problemas da vida real, os outros treze alunos avaliaram positivamente o método nesse aspecto. E no item sete, que diz respeito às impressões dos estudantes sobre a contribuição do método para a aprendizagem dos conceitos químicos, todas as respostas foram favoráveis à sua aplicação. Assim, os resultados refletem o envolvimento e a participação dos alunos durante a atividade que foi proposta, e o trabalho que foi realizado em grupo contribuiu individualmente para a formação de cada aluno.

Na pergunta número três, foi solicitado, ainda, que os alunos relatassem outras habilidades que eles acreditavam ter desenvolvido através do método de Estudo de Caso. As habilidades mais 
recorrentes nas respostas dos alunos foram criatividade: "acho que o estudo de caso me ajudou a desenvolver certa criatividade e responsabilidade e mais interesse em química"; "ter criatividade, coleguismo e envolvimento total com o grupo"; "trabalho em grupo, criatividade, desenvolver aspectos críticos e opinativos", responsabilidade: "acho que o estudo de caso me ajudou a desenvolver certa criatividade e responsabilidade"; interesse em estudar química: "Vontade de estudar a matéria"; comunicação, realização trabalhos em grupo, ouvir a opinião de colegas: "Aprendi a resolver problemas com muitas questões, também ouvir opiniões diferentes e com muitos pontos de vista". Conforme Sá e Queiroz (2009) o método de Estudo de Caso oferece a oportunidade dos alunos entrarem em contato com situações e problemas reais, possibilitando o desenvolvimento do pensamento crítico e de diversas habilidades, o que foi relatado pelos estudantes em suas respostas.

A última questão estava diretamente ligada à aceitação do método de Estudo de Caso pelos alunos. Todos os alunos responderam que gostaram de trabalhar com o método e apresentaram justificativas como: "Sim, porque aprendi a trabalhar em grupo. Foi interessante e contribuiu para a minha aprendizagem dos conceitos de química"; "sim, pois o caso é frequentemente visto atualmente e também o desenvolvimento do trabalho, para mim, foi divertido aliado com o aprendizado da matéria"; "sim, porque eu consegui assimilar a matéria com mais facilidade e de uma forma mais descontraída"; "sim, porque além de ser uma aula diferente serviu para facilitar a matéria e acho que incentivou os alunos a pesquisar"; "eu me senti mesmo como um estudante de química, que teria que analisar um medicamento, em outras palavras, eu incorporei o personagem".

Observou-se que os alunos adquiriram consciência sobre os perigos da automedicação, relacionando esse assunto com aspectos éticos, sociais, tecnológicos, econômicos, que fazem parte da realidade onde eles estão inseridos e, ao mesmo tempo, foi possível construir novos conceitos químicos e tornar o estudo das funções orgânicas relevante e motivador. Ficou nítido, tanto nas observações da professora como na fala dos alunos, que o método contribuiu para a compreensão dos conceitos químicos pelos alunos e também para a sua formação como cidadãos.

\section{Considerações Finais}

Os resultados apresentados permitem concluir que a escolha do método de Estudo de Caso para a realização desse trabalho se mostrou válida, pois contribuiu para que os estudantes assimilassem as características das funções orgânicas e de seus correspondentes grupos funcionais, ao mesmo tempo em que se conscientizavam dos perigos da automedicação. Todos os grupos conseguiram decidir corretamente se o medicamento que estavam pesquisando era ou não o responsável pelos sintomas da paciente e as apresentações por eles elaboradas incluíram 
conceitos de funções orgânicas, informações sobre o medicamento e a avaliação dessas informações pelos alunos.

O posicionamento dos estudantes em relação às afirmativas que dizem respeito a habilidades e conceitos que se pretendia aprimorar com o método aponta para a efetividade da proposta de ensino no seu desenvolvimento. Os resultados refletem o envolvimento e a participação dos alunos durante a atividade que foi proposta, e o trabalho que foi realizado em grupo contribuiu individualmente para a formação de cada aluno.

O tema "medicamentos", com enfoque na automedicação, escolhido para a elaboração da atividade aplicada, mostrou-se um assunto interessante, rico em informações químicas, propiciando aos alunos a construção do conhecimento químico e o desenvolvimento de habilidades que contribuem para a formação desses estudantes como cidadãos mais conscientes e críticos, tornando esse conteúdo químico relevante para os estudantes desta escola. Além disso, a participação da mãe de uma aluna como personagem do vídeo produzido por um dos grupos mostra que a relação do conhecimento químico com as situações reais, que tocam o aluno, faz com que o conhecimento adquirido se difunda positivamente na sociedade em que os alunos estão inseridos, permitindo que a química ultrapasse as fronteiras dos muros escolares e possa agir nos espaços sociais de seu entorno.

\section{Referências}

BOGDAN, R.; BIKLEN, S. Investigação qualitativa em educação: uma introdução à teoria e aos métodos. Porto: Porto Editora, 1994.

BRASIL. Secretaria da Educação Média e Tecnológica. Ciências da Natureza, Matemática e suas tecnologias: Parâmetros Curriculares nacionais - Ensino médio: Orientações Educacionais Complementares aos Parâmetros Curriculares Nacionais. Brasília. MEC/SEMTEC, 2002. Disponível em <http://portal.mec.gov.br/seb/arquivos/pdf/CienciasNatureza.pdf>. Acesso em 03/09/2010.

BRASIL. Ministério da Educação. Matriz de referência para o Enem 2009. Brasília: Ministério da Educação, 2009. Disponível em <http://www.enem.inep.gov.br/enem.php>. Acesso em 03/09/2010.

BRASIL. Ministério da Saúde. Agência Nacional de Vigilância Sanitária. Bulário Eletrônico. Brasília: Ministério da saúde, 2009. Disponível em <http://www4.anvisa.gov.br/BularioEletronico/>. Acesso em 08/09/2010.

CHASSOT, A. I. Para que $(m)$ é útil o ensino? Alternativas para um ensino (de Química) mais crítico. Canoas: ULBRA, 1995.

DELIZOICOV, D.; ANGOTTI, J. A. Metodologia do ensino de ciências. São Paulo: Cortez, 1992.

DELIZOICOV, D.; ANGOTTI, J. A.; PERNAMBUCO, M. M. Ensino de Ciências: fundamentos é métodos. São Paulo, Cortez, 2002.

FREIRE, P. Pedagogia da autonomia: Saberes necessários à prática educativa. São Paulo: Paz e Terra, 1996.

GATTI, B. A. Estudos quantitativos em educação. Educação e Pesquisa, v. 30, p. 11-30, 2004.

R. B. E. C. T., vol 6, núm. 2, mai-ago.2013 ISSN - 1982-873X 
LIPMAN, M. O Pensar na Educação. Petrópolis: Vozes, 1995.

LÜDKE, M.; ANDRÉ, M. E. D. A. Pesquisa em Educação: Abordagens Qualitativas. São Paulo: Pedagógica e Universitária, 1986.

MORAES, R.; GALIAZZI M. C. Análise Textual Discursiva. Ijuí: Unijuí, 2011.

LOPES, L. Quando uma aspirina pode fazer mal. Época, 2009. Disponível em: <http://revistaepoca.globo.com/Revista/Epoca/0,,EMI93890-15257,00.html>. Acesso em 29 set. 2010.

PAZINATO, M. S.; BRAIBANTE, H. T.; BRAIBANTE, M. E. F.; TREVISAN, M. C.; SILVA, G. S. Uma abordagem diferenciada para o ensino de funções orgânicas através da temática medicamentos. Química Nova na Escola, São Paulo, SP, v. 34, n. 1, p. 21-25, 2012.

PEREIRA, F. S. V. T.; BUCARETCHI, F.; STEPHAN, C.; CORDEIRO, R. Automedicação em crianças e adolescentes. Jornal de Pediatria. Rio de Janeiro. 2007, vol.83, n.5, pp. 453-458. Disponível em: $<$ http://www.scielo.br/scielo.php?script=sci_arttext\&pid=S0021-75572007000600010\&lang=pt >. Acesso em 29 set. 2010.

PERUZZO, F. M.; CANTO, E. L. do. Química na abordagem do cotidiano. 2 ed. São Paulo: Moderna, 1998.

SÁ, L. P.; QUEIROZ, S. L. Estudos de Caso no Ensino de Química. Campinas: Átomo, 2009.

SANTOS, W. L. P. dos; MÓL, G. de S (coord.). Química e Sociedade. Vol. Único. Ensino Médio. São Paulo: Nova Geração, 2005.

SANTOS, W. L. P.; MORTIMER, E. F. Tomada de decisão para ação responsável no ensino de ciências. Ciência e Educação, Brasília, DF, v.7, n.1, p.95-111, 2001. Disponível em: <http://www2.fc.unesp.br/cienciaeeducacao/viewarticle.php?id=115>. Acesso em: 06 out. 2010.

SILVA, O. B.; OLIVEIRA, J. R. S.; QUEIROZ, S. L. SOS Mogi-Guaçu: contribuições de um Estudo de Caso para a educação química no nível médio. Química Nova na Escola, São Paulo, SP, v. 33, n. 3, p. 185-192, 2011.

USBERCO, J.; SALVADOR, J. Química, volume 3:química orgânica.São Paulo: Saraiva, 2009.

VIEIRA, L. Química, saúde e medicamentos. Porto Alegre: Área de Educação Química do Instituto de Química da UFRGS, 1997.

Juliana Alba: Graduada em Licenciatura em Química pela Universidade Federal do Rio Grande do Sul.juli.alba@hotmail.com

Tania Denise Miskinis Salgado: Professora Associada do Departamento de Físico-Química da Universidade Federal do Rio Grande do Sul. tania.salgado@ufrgs.br

José Cláudio Del Pino: Professor do PPG Educação em Ciências: Química da Vida e Saúde - UFRGS e do PPG em Ensino - UNIVATES. delpinojc@yahoo.com.br 


\section{Automedicação: uma opção perigosa!}

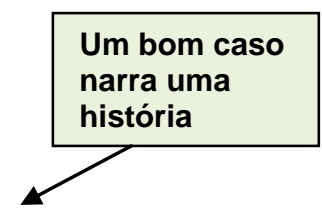

Na última semana, Diego não compareceu às aulas. Esse fato deixou seus colegas preocupados, pois final do próximo ano Diego pretende se formar e prestar vestibular, pois tem sonho de ser Engenhe Mecânico. Se continuar perdendo aula, dificilmente poderá concluir o ensino médio no próximo ano. representante da turma mandou uma mensagem via Orkut para Diego perguntando qual era o motivo sua ausência. Diego respondeu a mensagem por e-mail:

Caro colega, muito obrigado por sua preocupação, vou lhe explicar o que está acontecendo:

No último domingo, minha mãe não se sentiu bem, tomou alguns medicamentos, porém, com o passar dos dias, os sintomas pioraram. Ontem, depois da insistência de meu pai, ela foi ao Posto de Saúde onde foi atendida pelo médico Dr. Pedro:

- Bom dia! Muito prazer, em que posso ajudar a Senhora?

- Dr. Pedro, nos últimos dias, não tenho me sentido bem, estou com sintomas como dor de cabeça, tontura, náuseas, inchaço. Sofro de trombose faz anos. Tomei alguns medicamentos, mas não adiantou.

- E a senhora consultou algum médico antes de medicar-se, ou leu a bula dos medicamentos?

- Não, tomei todos por conta própria.

Dr. Pedro muito preocupado a alertou:

- As pessoas esquecem que todo medicamento tem efeito colateral. Automedicação abrange diversas formas pelas qual o indivíduo ou responsáveis decidem, sem avaliação médica, o medicamento como irão utilizá-lo para alívio sintomático e cura. A automedicação pode levar ao mascaramento sintomas de doenças em evolução, atrasando o diagnóstico e tratamento corretos, além de oferecer riscto para o uso de doses tóxicas. De acordo com dados do Sistema Nacional de Informações TóxicoFarmacológicas (Sinitox), 34.028 brasileiros sofreram intoxicações causadas por medicamentos em 2007, grande parte por acidente ou uso indevido. As pessoas não leem a bula, tomam o medicamento de olhos fechados sem saber os efeitos adversos que os fármacos (princípios ativos) podem causar. Quais os medicamentos que a senhora costuma tomar?

- Tenho eles aqui na minha bolsa já que frequentemente tenho uma dorzinha, não tenho condições financeiras de gastar com outros medicamentos: ácido acetilsalicílico (genérico), Cataflan, Paracetamol (genérico) e o anticoncepcional Ciclo 21.

Dr. Pedro falou para a minha mãe:

- Meu grupo de estudantes de química me ajudará a resolver o seu caso.

Força uma decisão estudos:

Na manhã seguinte Dr. Pedro enviou os medicamentos, e algumas informações para seu grupo de

- Colegas estou precisando da ajuda de vocês. Hoje atendi uma paciente que sofre de trombose vem apresentando sintomas como dor de cabeça, tontura, náuseas, inchaço. Já descobrimos através análises que tais sintomas estão relacionados com um dos medicamentos que ela toma sem prescriç̧ médica. Dentre os princípios ativos identificados nos medicamentos: ácido acetilsalicílico, paracetam etinilestradiol e diclofenaco, sabe-se que aquele que está causando tais sintomas é o que apresenta ema fórmula estrutural, anel benzênico, dois grupos funcionais orgânicos e é um dos de maior peso molecular. Vocês trabalharão em grupo, cada grupo analisará um medicamento apontando os dados que levem a crer que o medicamento em questão é ou não o responsável por tais efeitos. Para tanto vocês deverão orientar a paciente sobre o uso seguro de medicamentos fornecendo uma alternativa segura e mais barata de medicamentos, já que as condições financeiras da família não são das melhores.

Estou aguardando a resposta do Dr. Pedro, minha mãe continua com aqueles sintomas e tomar os medicamentos. Estou cuidando dela, pois meu pai trabalha o dia inteiro.

Um abraço.

Diego

Vocês fazem parte do grupo de estudantes do Dr. Pedro e têm a missão de ajudarem a resolver o caso e esclarecer o que está acontecendo.

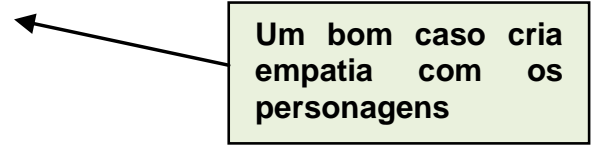




\section{Apêndice 2}

\section{Quadro 1-Questionário inicial}

Quais dos medicamentos abaixo você já tomou, conhece ou é utilizado por seus familiares, amigos, vizinhos?
( ) Paracetamol
( ) Cetoprofeno
( ) Amoxicilina
( ) Atenolol
( ) Aspirina, Melhoral, Calmador (ácido acetilsalicílico)
(..) Gelol
( ) Ibupropil (Ibuprofeno)
( ) Dramin
( ) Cataflan (Diclofenaco)
( ) Benegrip
( ) Dipirona (Anador)
( ) Anticoncepcional
( ) Naproxeno
( ) Vitamina C

( ) Outros:

Você costuma ler a bula do medicamento que vai utilizar?
( ) eventualmente
( ) não
( ) $\operatorname{sim}$

Quem receita os medicamentos que você costuma utilizar?

( ) médico ( ) farmacêutico ( ) mãe/ pai ( ) amigos ( ) vizinhos

A indústria farmacêutica fatura bilhões de dólares a cada ano e está sempre lançando novos medicamentos, mais inovadores e tecnologicamente mais avançados. Basta entrar em uma farmácia, por menor que seja, e observar a variedade de medicamentos existentes.

Você acha que existe alguma relação entre essas informações e a Química? Por quê?

\section{Apêndice 3}

\section{Questões sobre o caso:}

1) Identifique o principal assunto relatado no caso.

2) Pesquisa das características do caso.

a) Qual é o nome do princípio ativo do medicamento?

b) Qual é a fórmula estrutural do princípio ativo?

c) Qual é a fórmula molecular do princípio ativo?

d) Qual é o peso molecular do princípio ativo?

e) Existe anel benzênico na fórmula estrutural do princípio ativo?

f) De acordo com a bula, para que esse medicamento é indicado?

g) Quais são as contra indicações presentes na bula do medicamento em questão ou quando não se deve tomar esse medicamento?

h) Quais são as reações adversas presentes na bula do medicamento?

i) Quais são e quantos são os grupos funcionais orgânicos presentes na fórmula estrutural do princípio ativo?

j) Cite outra substância que apresenta o grupo funcional orgânico presente no medicamento e sua aplicação.

k) Qual é a cor da tarja na embalagem do medicamento e o que ela significa?

I) Qual é a diferença entre medicamentos genéricos e de referência? 
m) Como o problema apresentado no caso se relaciona às questões:

- sociais - econômicas - éticas

Compare estes dados com as informações dadas pelo Dr. Pedro.

3a) Qual é a gravidade da automedicação? Que riscos corre uma pessoa que se automedica?

3b) E no caso que estamos estudando, quais pessoas foram prejudicadas em consequência dos atos da mãe de Diego?

4a) Que medidas deveriam ser tomadas pela mãe de Diego antes de usar qualquer medicamento?

4b) Financeiramente, a mãe de Diego teria opções de consumir medicamentos com o mesmo princípio ativo, porém mais baratos. Quais são as alternativas que ela poderia encontrar em uma farmácia?

5) As medidas citadas na questão 4 são suficientes para orientar a mãe de Diego? Justifique.

6) Analisando todos os dados obtidos, o medicamento em questão pode ser considerado o responsável pelos sintomas citados no caso? Como você chegou a essa conclusão? Como a aplicação dos seus resultados se reflete no dia-a-dia das pessoas envolvidas no caso?

7) Reúnam todo o material e informações coletadas e elaborem uma apresentação para o resultado encontrado.

\section{Apêndice 4}

\section{Questionário de avaliação da atividade de Estudo de Caso.}

\section{Automedicação: uma opção perigosa.}

1) Em uma das etapas da realização dessa atividade caracterizamos e identificamos as funções orgânicas. Cite o nome de pelo menos duas funções orgânicas e apresente a estrutura do grupo funcional correspondente.

2) Depois de todas as atividades realizadas, o que você recomenda que se faça antes de tomar qualquer medicamento?

3) Várias atividades foram realizadas para chegarmos à solução do caso. Como você considera que essas atividades contribuíram para o aprimoramento ou desenvolvimento de algumas de suas habilidades, bem como na compreensão dos conceitos de química. Marque com $\mathrm{X}$ na alternativa que melhor expressar sua opinião. Para tanto considere: C - Concordo; CP Concordo parcialmente; I - Indeciso; DP - Discordo Parcialmente; DT - Discordo Totalmente.

\begin{tabular}{|l|l|l|l|l|l|l|}
\hline 1 & $\begin{array}{l}\text { Desenvolvi minha habilidade de investigação na busca de soluções } \\
\text { para resolver o caso }\end{array}$ & C & CP & I & DP & DT \\
\hline 2 & Desenvolvi minha habilidade de organizar informações & C & CP & I & DP & DT \\
\hline
\end{tabular}




\begin{tabular}{|l|l|l|l|l|l|l|}
\hline 3 & Desenvolvi minha habilidade de raciocínio & C & CP & I & DP & DT \\
\hline 4 & Desenvolvi minha habilidade de análise & C & CP & I & DP & DT \\
\hline 5 & Desenvolvi minha habilidade de classificação & C & CP & I & DP & DT \\
\hline 6 & $\begin{array}{l}\text { Desenvolvi minha capacidade de solucionar problemas e tomar } \\
\text { decisões diante de problemas da vida real. }\end{array}$ & C & CP & I & DP & DT \\
\hline 7 & $\begin{array}{l}\text { O método de estudo de casos contribuiu para a minha } \\
\text { aprendizagem dos conceitos de química }\end{array}$ & C & CP & I & DP & DT \\
\hline
\end{tabular}

Relate outras habilidades que você acredita ter desenvolvido com o método de Estudo de Caso:

4) Você gostou de trabalhar com o método de estudo de caso? Por quê? 